\title{
Investigación bibliotecológica y teoría: una relación ambigua
}

\author{
Héctor Guillermo Alfaro López *
}

Artículo recibido:

30 de noviembre de 2004.

Artículo aceptado:

4 de febrero de 2005.

\section{RESUMEN}

Entre la investigación bibliotecológica y la teoría existe una relación ambigua caracterizada por oblicuos encuentros y perseverantes desencuentros. Para salir de esa ambigüedad se propone la asunción programática y sistemática de la teoría como base fundamental de la investigación, lo cual permitirá forjar la teoría bibliotecológica. Esto a su vez coadyuvará a la consolidación de la práctica de investigación dentro del campo bibliotecológico y ello redundará en que éste alcance su propia autonomía e identidad respecto a los demás campos de conocimiento.

Palabras clave: Investigación; Teoría; Campo bibliotecológico; Autonomía; Identidad.

* Centro Universitario de Investigaciones Bibliotecológicas de la UNAM, México. galfaro@cuib.unam.mx 


\section{ABSTRACT}

Library Science research and Theory: an ambiguous relation Héctor Guillermo Alfaro-López

Between library science research and theory exists an ambiguous relationship characterized by oblique encounters and persevering discrepancies. To end with this ambiguity, the programmatic and systematic assumption of the theory is proposed as the fundamental basis of research, which will permit the forging of a library science theory. This, at the same time will help to consolidate research practice within the library science field, and will bring about its own autonomy and identity in regard to other fields of knowledge.

Keywords: Research; Theory; Library science field; Autonomy; Identity.

Sin duda, la teoría explicativa mantiene contacto, y el contacto más estrecho, con la experiencia, pero en tanto que la experiencia es el problema a aclarar y no un comienzo de solución. George CANGUiLhem

\section{$\infty$}

La experiencia, en el sentido de experiencia bruta, no desempeñó ningún rol, como no fuera el de obstáculo en el nacimiento de la ciencia clásica.

AlexandRe KOYré

$\infty$

Si la biblioteconomía sigue dependiendo en exclusiva de la práctica como única fuente de conocimiento, se convertirá no en una disciplina profesional innovadora, sino en un desfasado proveedor de práctica cotidiana.

EMILIO DELGADO LÓPEZ-CÓZAR

Para Arnulfo de Santiago como una breve muestra de sincera amistad
A lo largo de la centuria pasada se aceleró y agudizó un proceso de trans- formación en todos los órdenes del conocimiento que tuvo su origen en los albores de la modernidad. Ese proceso se caracteriza por un incremento de los conocimientos y su expansión, así como por su mayor segmentación especializada. En épocas anteriores a la modernidad el conocimiento estaba 
circunscrito a grupos favorecidos y reducidos de la sociedad, y se encontraba localizado en lugares muy específicos en los que era atesorado. Una compleja sucesión de acontecimientos históricos cambió paulatinamente ese estado de cosas, y produjo un incremento de conocimientos que ha ido difundiéndose entre los más amplios sectores sociales. Pero esa misma ampliación del conocimiento se encuentra tensionada por una tendencia cognoscitiva que conduce a la segmentación de ese conocimiento, al grado de que, por lo que se evidencia en el terreno epistemológico a nivel histórico, se ha establecido una correlación ecuacional: incremento del conocimiento $=\mathrm{a}$, menor unidad del mismo; lo cual conduce a mayor polarización del conocimiento en orbes cada vez más acotados y especializados. Esa correlación ecuacional se muestra indetenible y sigue su propia inercia que conduce a una sectorización más microscópica: el incremento del conocimiento en orbes mayormente especializados, que dan lugar a orbes interiores aún más acotados.

Toda esa dinámica del conocimiento propicia el despliegue de una serie de tendencias y movimientos que están en consonancia con la mencionada correlación ecuacional para sustentarla y consolidarla. Esta marcha del conocimiento impulsa el desarrollo de las tecnologías que son receptoras y divulgadoras precisamente de esa expansión del conocimiento, el cual en términos neutros y de volumen es concebido como información. La imprenta es el primer hito moderno en ese devenir tecnológico sustentador de la expansión del conocimiento. Esa misma expansión y segmentación especializada se ahonda conforme mayor impulso obtiene el desarrollo y la depuración de la esfera tecnológica, lo cual a su vez repercute en la expansión y segmentación del conocimiento.

Al interior de esos orbes segmentados se da una tendencia de diferenciación (especialización) interna a partir de la gestación y delimitación de una serie de prácticas que son producto (reflejo) y respuesta a la tendencia externa de expansión y especialización. Queda así instaurado un campo de conocimiento donde cada una de las prácticas específicas y diferenciales que lo constituyen llevan a cabo una función determinada. Ahí, para desenvolverse, cada práctica hace uso del capital de conocimientos acumulado en el campo desde su origen, incluso desde antes que se perfilase como un orbe especializado. A partir de ese uso de conocimientos acumulados las prácticas generan a su vez conocimientos cuya conjunción unitaria conforma la organización cognoscitiva de la disciplina del conocimiento, la cual es el factor vertebrador interno y de presentación externa del campo de conocimiento. Todo ese capital de conocimiento especializado que producen las prácticas redunda en la integración de una disciplina especializada de conocimiento. Ahora bien, según sea el objeto de conocimiento, su orientación (respecto a la realidad y a 
ese objeto de conocimiento, que incluso en la antípoda del especialismo puede ser considerado de una manera omniabarcadora $)^{1}$ y su grado de especialización, cada campo de conocimiento hace así uso de la tecnología; esto es, como un medio o instrumento de apoyo para su desenvolvimiento, ya sea para recibir a través de ella el conocimiento o para vehiculizar ese conocimiento que los campos generan.

Como se indicó previamente todo este proceso hizo eclosión en el transcurso del siglo XX, múltiples fenómenos histórico sociales, que sería arduo reseñar, propiciaron una aceleración del movimiento recursivo (donde lo causante es a su vez causado por aquello que causó) entre conocimiento y tecnología, que disparó el incremento de información; aceleración que frente a la vehiculización que hace de ella la tecnología puede ser puesta nominalmente (que no realmente del todo) a disposición de cualquier individuo. Las décadas finales del siglo XX testimonian el ascenso de la tecnología cibernética que, según sus apologetas, ha realizado el gran sueño de masificar y democratizar la información. Excedente de información e impacto de las nuevas tecnologías que deriva en la reconfiguración o el ajuste de la organización de los campos de conocimiento ya establecidos y consolidados. Pero en otros casos conlleva la constitución de otros campos o, en última instancia, ayuda a terminar de constituirse a algunos más. Es en el ojo de esta turbulencia dentro del horizonte integrador de los campos de conocimiento en donde se agita la bibliotecología.

Es en el siglo XIX donde coinciden la aparición de la biblioteca pública con la gestación de la llamada bibliotecología científica. Esta última entrañaba una reconstitución de la concepción de las bibliotecas, para comprenderlas ahora como centros de información, educación y recreo sociocultural, lo cual se correspondió con una redefinición de los bibliotecarios como agentes difusores de la información. El fundamento de tal concepción bibliotecológica obedecía a que se la concebía como una ciencia de la selección organizada y de la difusión de los fondos librarios. Esta situación señalaba el paso decisivo en su constitución como campo de conocimiento, y por eso mismo se iba dando en esa fase inicial el proceso interno de gestación y diferenciación de sus primeras prácticas internas. Hacia las primeras décadas del siglo XX surge la necesidad de promover la investigación bibliotecológica para, a través de ella, hacer frente cognoscitiva y sistemáticamente al incremento de información y a las transformaciones tecnológicas que estaban desarrollándose en ese momento.

1 Para una más amplia explicación de lo que es un conocimiento, disciplina omniabarcadora de la realidad, véase mi estudio: "La otra lectura. Una contribución al problema de la lectura en bibliotecología”, en: Revista de Investigación Bibliotecológica. 
Las primeras tentativas de constitución de investigación no lograron arraigar firmemente. En 1936 Douglas Waples publicó su Investigating Library Problems que en esencia era una guía para la investigación en bibliotecología. Desde una perspectiva más consistente que lo que el anterior enfoque meramente pragmático había hecho, intentaba buscar las bases sociales de las instituciones bibliotecarias evaluando el servicio que prestaban, para lo cual empleo los métodos de investigación que se implementaban en otros campos de conocimiento. Es de señalarse que en ese inicial intento de fundación de investigación bibliotecológica $\mathrm{D}$. Waples no se encontraba solo, debido a que estaba respaldado por la Graduate Library School of Chicago (GLSCH). La obra de Waples sólo puede entenderse en el marco de esta institución, que fue la primera escuela de bibliotecología en que se planteó como prioritaria la necesidad de investigar y hacer teoría para fundamentar la disciplina bibliotecológica. Este intento pionero ha de comprenderse como la inicial toma de autoconciencia que hace la bibliotecología para fundamentarse durante su fase de constitución (en este caso particular, la bibliotecología estadunidense) como campo de conocimiento a partir del parámetro teórico. Conditio sine qua non para luego alcanzar la fase de autonomía. Lo que define un campo de conocimiento autónomo es la elaboración de su propia teoría, y que además dé una explicación conceptual de sí mismo.

El hombre visionario que propició en la década de los 30 de la pasada centuria ese gran logro de la GLSCH (y de la bibliotecología en general) fue su primer director Louis Round Wilson, quien buscando romper con los ancestrales y profundos conservadurismos del gremio bibliotecario le dio a su escuela una nueva base cognitiva para empujar la bibliotecología hacia la senda de la investigación, como nos lo testimonia Jesse Shera, egresado él mismo de esa escuela en su gran momento:

Wilson habría de dejarle a la escuela la mayor fuerza única de su generación en la bibliotecología norteamericana y en educación bibliotecológica norteamericana. Como nuevo director Wilson le dio a la escuela un marco filosófico y a la vez una estructura organizativa. La teoría y el método habría de anteceder a la técnica (...) pero quizá la mayor innovación fue que por primera vez en la educación bibliotecaria la biblioteca fue considerada como un fenómeno social, y a que toda su investigación e instrucción se le dio un enfoque social. ${ }^{2}$

2 J. Shera, Los fundamentos de la educación bibliotecológica. México, CUIB-UnAm, 1990, p. 249. "En una reunión especial de la Association of American Library Schools, del Board of education for Librarianship, efectuada en Chicago el 31 de diciembre de 1940, para honrar a la Graduate Library School, Wilson enlistaba siete objetivos del programa escolar:

1. Desarrollar una teoría o filosofía de la bibliotecología.

2. Extender y aplicar la búsqueda de principios guía que fueran aplicables a varias 
La tentativa de D. Waples no fructificó, ni tuvo resonancia inmediata en el proceso de constitución del campo bibliotecológico. Entre las múltiples razones por las que en ese momento no arraigó la investigación en el campo bibliotecológico cabe señalar dos, que en gran medida continúan lastrándola y que de hecho repercuten en el conjunto del campo: la absorta centralización de la atención en los procesos constitutivos internos de la biblioteca, y una concepción del conocimiento bibliotecológico como mero conocimiento aplicado. Como éstos son elementos importantes del desarrollo de mi argumentación, baste por el momento sólo su enunciación.

Lo que no pudo llevar a cabo D. Waples con su obra lo realizó el proceso histórico social propio del siglo XX. Las grandes convulsiones, hecatombes y transformaciones profundas de la pasada centuria produjeron las consecuencias ya explicadas en los ámbitos tecnológico y de la información. Paralelamente a este impulso o, más exactamente, como consecuencia de él la bibliotecología tuvo que replantearse a sí misma integralmente. Lo cual era comprensible porque eran precisamente esas transformaciones en la información y la tecnología las que tocaban y removían sus propias bases. Se trataba de un campo de conocimiento en proceso de constitución pero que además se encontraba en pleno centro de las transformaciones que recorrían el horizonte de los campos de conocimiento. Transformaciones que a otros campos les dio la oportunidad de reafirmar y consolidar su organicidad y fundamentos, mientras que a la bibliotecología la obligaba a ponerlos en cuestión y a generar incertidumbres sobre los caminos a seguir. Todo esto coadyuvó a replantear e instaurar la investigación bibliotecológica sobre bases más consistentes, pero en la medida en que su trayectoria de consolidación se da en consonancia con los cambios tecnológicos y de la información (técnoinformativos) se verá afectada por indefiniciones y desvíos en cuanto a su concepción y elaboración epistemológica. Del replanteamiento que hace de sí misma para encontrar una definición en respuesta a esos cambios, emergerá una tendencia que busca mimetizarse con las fuerzas que impulsan

subdivisiones de la bibliotecología.

3. Capacitar a los estudiantes competentes para: a) Desempeñar sus actividades profesionales de acuerdo con estos principios y filosofía. b) Enseñar las varias ramas de la bibliotecología sobre esta base, y c) Efectuar investigaciones que contribuyan a clarificar mejor los principios y métodos de evaluar la práctica bibliotecaria y a solucionar los problemas de una biblioteca.

4. Desarrollar en el estudiante una actitud crítica y experimental, y a tener un punto de vista hacia la bibliotecología.

5. Promover las publicaciones

6. Incrementar la efectividad educativa de la biblioteca

7. Desarrollar una mejor comprensión de los medios para comunicar ideas a través de los impresos, la radio y el cinematógrafo" Ibid., pp 249-250

Como se aprecia éste es un programa adelantado que sigue aún vigente y clamando en la actualidad por su completa realización. 
el avance técnoinformativo, bajo el supuesto de que son elementos connaturales a la bibliotecología. Lo cual producirá un sutil desplazamiento del eje rector (paradigma) del campo y transfigurará la orientación propia y normal que seguía hacia su futuro; y bloqueará además la proyección de su pasado en el presente, a semejanza de una cuña que se incrusta entre la continuidad del pasado con su proyección futura.

La forma sobre cómo esto deja su impronta en la investigación muestra que no se tiene una completa claridad respecto a su especificidad en la dinámica del campo ni de sus relaciones con las demás prácticas, ni tampoco sobre el carácter determinativo de su actividad y funciones dentro del campo. Y por otra parte es orientada prioritariamente hacia la investigación aplicada, y relega la construcción teórica; la cual, como veremos, es consustancial al proceso de investigación. Como mera acotación; esto es, sin invertir ni tergiversar términos, la investigación teórica debería ser un factor primordial para el desarrollo de aquella investigación que se precie capaz de producir un conocimiento original que responda a las necesidades propias de un campo de conocimiento, y que no hace de la desvaída imitación una virtud cognoscitiva. Tales son, pues, los factores que han dado de bruces en la indefinición y la incertidumbre, en la elaboración y el despliegue epistemológico de la bibliotecología. Y esto, en un orden más profundo, contribuye a la postergación de su auténtica fundamentación como disciplina de conocimiento, autónoma y con identidad propia.

Cabe señalar que en la exposición precedente se explicaron las tendencias genéricas y a nivel global del desenvolvimiento del campo bibliotecológico, lo que hace pertinente especificar ahora lo que viene a continuación. Esas tendencias antes explicadas adquieren especial relevancia e ilustración en aquellos países que no pertenecen al mundo desarrollado, como son los países latinoamericanos, que motivan particularmente la presente indagación. Todo lo cual nos sirve como marco de referencia para plantear los problemas a los que se busca aquí dar respuesta: ¿Cuál es (o debe ser) el carácter distintivo y definitorio de la investigación bibliotecológica y qué tipo de relaciones tiene (o debería tener) ésta con la teoría? Y ¿cómo contribuye a la consolidación (autonomía) del campo bibliotecológico la práctica de la investigación? Para contestar estas interrogantes adelanto una premisa hipotética: es a partir de resolver la ambigüedad que ha surcado las relaciones entre investigación bibliotecológica y teoría como se encontraran las vías que responden a los problemas que se plantean en las preguntas enunciadas. Lo cual finalmente abre una brecha hacia un objetivo que incluso desborda con largueza a esta indagación: la constitución de una identidad claramente determinada y diferencial de la bibliotecología. 
En la medida en que las nuevas tecnologías y el crecimiento desmesurado de la información impactan a las sociedades y a los campos de conocimiento, el campo bibliotecológico es sacudido hasta sus cimientos, y al buscar asimilar ese movimiento se va gradualmente fundiendo con él, con lo que pierde de vista su propia especificidad diferencial y posterga su autofundamentación identitaria. Esto repercute en la producción cognoscitiva de la propia investigación bibliotecológica, que buscando definir su carácter particular termina por ser reflejo de aquello de lo que trataba de dar razón. Al mimetizarse la investigación con aquello que pretendía explicar pierde la distancia requerida para conocer el objeto en cuestión, distancia que le es necesaria para que su proceso de conocimiento le permita autodefinir y reafirmar su propia especificidad y diferencia respecto de lo que busca conocer, su objeto de conocimiento. Veamos un ejemplo prototípico de esa tendencia mimética de la investigación bibliotecológica que nos orientará en la resolución de los problemas planteados. Se ha elegido una investigación particular para ilustrarnos respecto a la mencionada tendencia mimética: la investigación de Neysa Guevara titulada ejemplarmente Teoría y práctica de la bibliotecología. Esta investigación reúne con mérito los atributos necesarios para ser criticada, debido a las ambiciones de su propuesta y las contradicciones que la cruzan a todo lo largo de su desarrollo.

Ahora bien, por cuestión de método y de los objetivos aquí buscados me he circunscrito en particular al análisis y la crítica del texto de N. Guevara, lo que por otra parte implica dejar afuera autores como Herbert Goldhor y Jesse Shera, los cuales dentro de su particular concepción guardan cercanía con las propuestas de N. Guevara. Por método he buscado circunscribir con mayor precisión y concreción el tema: nuestra realidad regional, lo cual conlleva la elección de un autor latinoamericano. En cuanto a los objetivos no se busca con ellos sólo hacer un mero acercamiento comprensivo a un texto particular sino que éste, por sus características específicas, sea una plataforma que nos proyecte hacia lo arriba enunciado. Al responder a la problemática, hipótesis y objetivos presentados se estará en posibilidad también, por sucesión y fundamentación metodológica, de aplicar la perspectiva de indagación en el futuro para abarcar una región más amplia y por consiguiente a otros autores como Goldhor y Shera, cuyas propuestas son productos que buscan dar respuesta a la circunstancia que les es propia, el mundo anglosajón. Una teoría, cualquier teoría o simplemente propuesta teórica debe ser primeramente comprendida al trasluz de la circunstancia social que le dio origen, para empezar así a ofrecer todos sus rendimientos cognoscitivos. Separarla de su circunstancia para contemplarla como mero artefacto abstracto, racional, autónomo, conduce a su desnaturalización; esto es, a anularla en cuanto a su propio fundamento epistemológico. 
Aunque la publicación del libro de N. Guevara data de 1995 y durante ese tiempo a la fecha la investigación bibliotecológica ha hecho grandes progresos en su consolidación, la problemática que fractura la investigación de N. Guevara sigue vigente. Para mejor ilustrar esa problemática me remito directamente a los párrafos donde queda sintetizada la tesis fuerte del libro que, por no tener otra opción, citaré en extenso:

Como ya hemos expresado, en esencia, el objeto de estudio de la bibliotecología es un acto comunicacional centrado en un proceso de transferencia de conocimientos registrados que a la vez que procura conocimientos, genera otros nuevos. Desde el punto de vista de su carácter de tecnología social, su teoría es la base del sistema de reglas que prescriben el curso de la acción óptima para hacer posible la transferencia de conocimientos registrados, trabaja según decisiones tomadas a la luz del conocimiento teórico, sobre el cual es la mejor forma de recuperar, organizar y difundir el conocimiento registrado.

La teoría bibliotecológica es tecnología porque tiene relevancia para la acción, porque suministra conocimientos sobre los objetos de la acción, sistemas documentales, de información o de archivos, por ejemplo, y porque se refiere a la acción misma, las decisiones que preceden y guían la puesta en marcha de cualquiera de estos servicios. Es social porque tales sistemas son los que optimizan las relaciones entre los hombres en su eterna búsqueda de conocimientos registrados. Es cierto que planificación y toma de decisiones en el campo bibliotecológico no son aplicaciones de ninguna teoría científica pura, son ellas mismas teorías operativas que utilizan de alguna manera procedimientos cognoscitivos.

La teoría para la acción bibliotecológica aspira a establecer normas estables, que permitan con éxito la relación hombre-sociedad mediante el proceso de transferencia de información registrada; indica cómo proceder para conseguir ese objetivo, da instrucción para realizar un determinado número de actos para alcanzarlo. Aspira también a la previsión bibliotecológica, a sugerir como influir en determinadas circunstancias para producir ciertos hechos o evitarlos. ${ }^{3}$

Pasemos a explicitar la propuesta contenida en estos párrafos a partir de lo que en cada uno de ellos se pretende fundamentar. En el primero la autora enuncia lo que considera que es el objeto de estudio de la bibliotecología: un acto comunicacional que propicia la transferencia y generación de conocimientos registrados. Con lo que los naturales objetos de estudio de la bibliotecología, la biblioteca y el libro, dejan de ser la finalidad para constituirse en vehículos del "auténtico" objeto de estudio, el acto comunicacional. La

3 N. Guevara. Teoría y práctica de la bibliotecología, Caracas, Fondo Editorial de la Facultad de Humanidades y Educación de la Universidad Central de Venezuela, 1995, pp. 56-57. 
enunciación de este objeto deja de manifiesto la base sobre la que esta investigadora se apoya, y que es visible a lo largo de todo un capítulo de su libro, la teoría de la comunicación. Teoría que precisamente va a tener su mayor impulso y consolidación en el mismo proceso de eclosión técnoinformativa del siglo XX y que agita al campo bibliotecológico.

En el siguiente párrafo se afirma que la sustentación teórica que debe tener la bibliotecología es de carácter funcional y sistémico para de manera práctica poder llevar a cabo eficientemente las funciones sustanciales que le son propias: recuperar, organizar y difundir el conocimiento. Para llegar a esto la investigadora hace uso de la teoría de sistemas, de donde deriva a una sustentación de teoría aplicada. De este modo la teoría no es una finalidad per se para la investigación sino un mero instrumental de objetivos prácticos de la bibliotecología. Sobre este aspecto que es nodal en mi argumentación ahondaré más adelante.

En el tercer párrafo N. Guevara nos asesta su definición de lo que entiende por teoría bibliotecológica: "La teoría bibliotecológica es tecnología porque tiene relevancia para la acción, porque suministra conocimientos sobre los objetos de la acción..." (cursivas mías). Para ella, pues, por definición la bibliotecología es una tecnología social motivada por la acción y dirigida a la acción de los servicios (bibliotecarios) o sistemas que facilitan las relaciones entre los hombres, y entre éstos la búsqueda de conocimientos registrados. Con esta definición queda manifiesta y de manera por demás incontrovertible, la señalada tendencia hacia el mimetismo de la bibliotecología con respecto a los fenómenos de la tecnología y la información. En la parte correspondiente a su texto en la que busca justificar y fundamentar semejante definición, la investigadora cae en errores de comprensión y otras inconsecuencias respecto a la diferencia entre técnica y tecnología, así como entre ciencia y técnica y su derivación tecnológica, y es ahí donde subyace su dictum instrumental, que hace a la propia tecnología inapropiada para ser, a su vez, fundamento de un conocimiento. Por naturaleza la tecnología es una derivación, extensión de un cierto tipo de conocimiento que hace uso de aquella como un medio, no como una finalidad para fundamentarse a sí mismo por mediación de la tal tecnología.

Como una mera acotación marginal cabe señalar que una de las graves consecuencias que derivan de una concepción de la Bibliotecología como tecnología (por muy social que la estime N. Guevara) es la deshumanización; esto es, la ruptura con su pasado, con su tradición, con su fundamento humanístico. Lo cual queda en evidencia a lo largo de una investigación como la que hace Guevara, quien busca responder a las preguntas ¿qué es la bibliotecología? y ¿cómo conocer la bibliotecología? En la que brilla por su ausencia el ser humano. 
En el antepenúltimo párrafo se ratifica el carácter operativo de las teorías en bibliotecología. Y en el último párrafo se completa esto afirmando que "La teoría para la acción bibliotecológica aspira a establecer normas estables..." De esta forma la tesis de la investigadora termina a tambor batiente con una preclara visión practicista, esto es, funcionalista y prescriptiva de la bibliotecología.

Contra las apariencias, no es labor perdida la de interpretar esos párrafos cuya endeblez los hace fácilmente contrargumentales, porque la concepción que en ellos hay sobre la bibliotecología los hace dignos del análisis y la reflexión crítica. Sólo así podremos apreciar lo positivo y lo fallido; esto es, lo contradictorio de su propuesta y, al trasluz de ello, perfilar otra senda a seguir para la bibliotecología. El acierto de la propuesta de esta investigadora es su clarividencia sobre la necesidad de fundamentar la investigación bibliotecológica en la teoría, lo cual queda de manifiesto en el empeño que pone en su propia investigación. Pero el camino que sigue para lograrlo es contradictorio y acaba conduciéndola a un callejón sin salida, lo cual queda de manifiesto en los mismos instrumentos teóricos que utiliza así como en la finalidad hacia la que la conducen, y ésta es instrumental. Lo que es también visible en la noción que tiene sobre la teoría y sobre cuál de éstas debe ser la adecuada para la bibliotecología. Todo ello la lleva a darse de bruces con el mimetismo tecnológico, como nos lo exhibe su definición de bibliotecología como tecnología.

N. Guevara afirma una y otra vez en su libro la necesidad de incorporar la teoría a la investigación para desde allí generar la teoría bibliotecológica. Cosa que pregona con el ejemplo al mostrar todo el zurcido de las teorías de las que hace uso. Teorías tomadas de otras disciplinas pero que concuerdan explicativamente con los procesos sociales y cognoscitivos tecnoinformáticos en boga. Así, para sustentar cada aspecto que trata sobre la bibliotecología hace uso de teorías diferentes que, muy laxamente, logra unificar entre sí. Cada una de tales teorías, sin ser pasada previamente por la criba de la crítica, es forzada para ser implementada explicativamente sobre el objeto o aspecto en cuestión. Mas para la autora esto tiene su propia justificación: suministrar elementos teóricos de carácter funcional para fundamentar una concepción funcional de la bibliotecología, lo cual evidencia que la noción que en el fondo tiene de la bibliotecología es la de una actividad esencialmente pragmática que sólo requiere algunos elementos teóricos ad hoc para desempeñar más comprensivamente esa vocación práctica. Todo lo cual hace que N. Guevara nunca se planteé que es sólo a partir de la auténtica asimilación, procesamiento y transformación crítica de las teorías usadas como se puede generar una teoría unitaria y coherente propia; esto es, la teoría bibliotecológica por la que ella tanto clama, como vocación de la investigación. Asimismo la argumentación de esta 
investigadora se encuentra recorrida por el supuesto de que la bibliotecología sólo puede (y debe) desarrollar investigación aplicada. Todo el tiempo establece que lo propio de la investigación es estar destinada a su aplicación, e incluso sostiene la inviabilidad de la investigación pura, es decir, meramente teórica. Todo eso le sirve para fundamentar su visión, su definición tecnológica de la bibliotecología. Pero al estar respaldada exclusivamente por una concepción de investigación aplicada como la única viable para la bibliotecología, esa definición muestra claramente la contradicción e insuficiencias que la cruzan. La investigación es coherente con su argumentación, pero no es consistente con la realidad del campo bibliotecológico.

Toda la investigación de N. Guevara engloba en un conjunto indiferenciado la totalidad del campo bibliotecológico sin vislumbrar la especificidad y diferenciación de cada una de las prácticas que lo integran, lo que le impide comprender la dinámica de actividad e interrelaciones que se dan entre ellas, y sólo entiende ese conjunto indiferenciado como una entidad signada por el funcionalismo práctico. Tal insuficiencia de su visión se entiende ya que en gran medida esto ha sido determinado porque la biblioteca y sus procesos constitutivos internos de carácter esencialmente funcional, ha centrado la atención cognoscitiva del campo, por lo que requiere una sustentación particular y diferencial respecto a las demás prácticas. Coincido con N. Guevara en que se requiere una sustentación teórica, pero no sólo privilegiadamente como investigación aplicada, porque esto acaba por igualar y homogenizar la investigación con las demás prácticas, y difumina su cualidad estratégica de articuladora y fundamentadora (teórica) de las otras prácticas de campo. Para que esa función pueda llevarla a cabo la investigación ha de sacudirse el estigma que la destina prioritariamente (y en un código no escrito, casi exclusivamente) a la aplicación. La investigación aplicada de hecho seguirá desarrollándose durante algún tiempo por cuenta propia, mientras encuentra la dirección que la lleve a su necesaria y lógica fundamentación teórica; esto es, hasta que haga explícito el basamento teórico sobre el cual siempre se ha erigido. Quede claro que la investigación aplicada per se contribuye muy limitadamente a la forja de una auténtica teoría bibliotecológica, la cual además vendrá a ser la base de autodefinición de la práctica de investigación, que así podrá asumir su rol propio en la dinámica interactiva de las prácticas de campo. Así pues, ha de comprenderse lo que aquí se busca con las distinciones señaladas. Por el momento la investigación aplicada seguirá cumpliendo con sus funciones necesarias e inmediatas, pero no le pidamos lo que no puede dar y que sólo puede abtenerse mediante la indagación plenamente teórica. Lo que por otro lado nos evitará caer en ese equívoco de definir a la bibliotecología como tecnología, lo cual encubre un mimetismo que la lleva a 
perder de vista su identidad específica. De ahí que no sea tarea ociosa llevar a cabo la crítica de una investigación que muestra de forma clara y sin subterfugios esa tendencia que aún prima en nuestros días en el quehacer cognoscitivo de la bibliotecología. Veamos ahora el problema de la teoría en sí mismo, para luego comprenderla concomitantemente al trasluz de la práctica de la investigación del campo bibliotecológico.

Paralelamente a la constitución de los campos de conocimiento y a que dentro de ellos se consolida la práctica de la investigación, resurge la antigua problemática que establecía una línea distintiva entre conocimiento puro y conocimiento práctico. Disyuntiva que en su origen desveló al pensamiento griego. Para los antiguos griegos y sus estructuras sociales, la mentalidad a ellas correlativa concebió el conocimiento en una doble vertiente: contemplativo y activo, que incluso se correspondían con formas de vida contemplativas y activas. El conocimiento contemplativo tenía como factor generativo la teoría, mientras que el conocimiento activo era motivado por la resolución de situaciones inmediatas, materiales. El conocimiento contemplativo estaba auroleado por los prestigios de la perfección intelectiva. Esto se entiende cuando discernimos el sentido tanto etimológico como concreto que el concepto de teoría tenía para los griegos. Teoría proviene del verbo theorein que significa contemplar. Por lo que teoría es el acto de contemplación que trasciende lo inmediato, por eso es más que un simple mirar. Es la contemplación de la esencia del mundo, lo que muestra las profundas relaciones entre las cosas y lo que le da unidad a la realidad. Esta concepción primigenia, sustancial, de teoría fue elaborándose y reelaborándose cada vez de forma más compleja hasta gradualmente convertirse en esa estructura abstracta, cognoscitiva, como se la entiende actualmente. Durante ese largo recorrido de transformación, la teoría fue cerrando la brecha que la distanciaba del conocimiento activo, hasta llegar a conjuntarse con él, aunque siempre mantuvieron reservas mutuas. Sin embargo ese acercamiento muestra la necesidad de complementariedad de una y otra formas de conocimiento cosa que requiere para mejor y más profundamente proyectarse en la consecución de sus objetivos. Mas esas reservas mutuas resurgen en cualquier momento dependiendo de la concepción y actitudes inmediatas que en cada época, los individuos o grupos sociales consideren prioritarias.

La distinción que se hace entre investigación pura y aplicada se corresponde con la tendencia segmentadora y especializadora que determina la orientación del conocimiento en la actualidad, además de que los intereses y fuerzas histórico-sociales que marcan y empujan esa tendencia privilegian implícitamente la dimensión práctica del conocimiento. Lo cual impide que se vea el largo recorrido histórico que ha llevado al acercamiento de ambas 
formas de conocimiento y los logros a que ello ha dado lugar. El colofón es el desconocimiento y hasta la desconfianza (sino es que el temor), frente al universo de la teoría per se, como subyace en la investigación de N. Guevara.

Para volver a cerrar la brecha entre ambas formas de conocimiento sería pertinente volvernos hacia la comprensión de la teoría misma y acceder de nuevo a sus atributos: sus propiedades y sus potencialidades, lo que nos permitirá comprender las relaciones e interacciones que guarda con la práctica. Se hará así clara su pertinencia para la investigación bibliotecológica y ello nos permitirá definir mejor el papel que juega la teoría en el campo bibliotecológico. Partamos de la premisa de que la teoría no es una ornamentación lujosa del conocimiento sino una necesidad humana. Necesidad que se autorganiza cognoscitiva y sistemáticamente para contemplar la verdad oculta del Ser del mundo, como nos lo explica inmejorablemente Edgar Morin en su concepción de teoría, por lo que es pertinente reproducirla en extenso:

Una gran Doctrina o Teoría depende del principio que legisla y gobierna al mundo, y constituye un analogon abstracto/ideal del funcionamiento del Universo. De este modo, permite contemplar la verdad oculta del Ser del mundo; se comprende en adelante el sentido contemplativo original del término "teoría", que indica el carácter existencial de ésta. Además, como hemos visto y volveremos a ver, en el corazón de las doctrinas o teorías hay un núcleo de ideas rectoras, que responden a las grandes obsesiones cognitivas, aseguran su comunión ontológica con lo real y procuran un sentimiento de plenitud. Alrededor de este núcleo se articulan justificaciones empíricas, lógicas, ideológicas que establecen en todos los niveles la adecuación entre la teoría y lo real. En estas condiciones, lo que se establece entre la teoría y lo real no es solamente una bienaventurada y evidente armonía, también se opera una identificación secreta, por magia analógica, entre el analogon teórico y el mundo real. En adelante, la teoría le da al espíritu, en su comunicación que deviene comunión con el mundo, el sentimiento evidente de poseer al mundo y ser poseído por él. De este modo, la contemplación teórica de la verdad se alía con la posesión poseída de la verdad. ${ }^{4}$

Retengamos los elementos centrales de la teoría según nos los explica Edgar Morin: depende del principio que legisla y gobierna al mundo; es un analogon abstracto/ideal del funcionamiento del universo, por lo que permite contemplar la verdad oculta del Ser del mundo. En ella hay un núcleo de ideas rectoras que responden a las grandes obsesiones cognitivas y aseguran una comunión ontológica con lo real. Alrededor de este núcleo se articulan 
justificaciones empíricas, lógicas e ideológicas que establecen en todos los niveles la adecuación entre la teoría y lo real. Por lo que la teoría le da al espíritu en su comunicación, que deviene comunión con el mundo, el sentimiento de poseer el mundo y de ser poseído por él.

El ser humano no sólo se dirige al mundo para satisfacer necesidades inmediatas, y por extensión tampoco se conforma con la mera actividad práctica, todo lo cual sólo lo hace deslizarse por la superficie material del mundo. Esa insatisfacción, esa inconformidad, se nutre de la dimensión espiritual, base de lo humano que impele a ir más allá de la esfera de lo inmediato para entrar en comunión con el mundo, comunión que significa conocerlo en su verdad profunda. La contemplación, fundamento primero de la teoría, deviene conocimiento, pero éste es de una cualidad específica que le permite precisamente en esa esfera profunda, esencial, del mundo, encontrar la verdad. De ahí la voluntad de teoría del espíritu humano, que es asimismo una necesidad humana.

La teoría, a diferencia de la mera actividad práctica, que deviene inmersa en el flujo inmediato de la realidad, se desliga de la inercia inmediata para tomar distancia, una perspectiva que le permita forjar una construcción (analogon) que de manera abstracta, ideal, reproduzca el funcionamiento del mundo. Esa construcción se levanta sobre un conjunto de ideas, acordes con la parte o partes de la realidad a la que se busca darles una explicación teórica. Tal conjunto de ideas no son una entidad estática y aislada, en su ser ideal y abstracto establecen niveles de interacción entre ellas y con el mundo. Sus mutuas relaciones de organización lógica se proyectan sobre la realidad empírica para dar razón de ella, es la fase de explicación (objetividad) de la teoría, y a su vez esa dimensión empírica se introduce en el entramado lógico de las ideas para constituirlas o reconfigurarlas, fase de comprensión (subjetividad), lo cual va regulando la adecuación entre la teoría y lo real. La construcción teórica genera, una vez que se encuentra constituida y definida, mecanismos de explicación de sí misma que según cómo sean manejados pueden dar lugar incluso a una armazón ideológica protectora. ${ }^{5}$ Armazón que al endurecerse puede incluso convertirse en un corsé que asfixia a la propia teoría, y paralizar la interacción entre las ideas y la realidad. De esa forma la teoría establece una relación ontológica con la realidad; esto es, muestra la verdad del Ser y produce ese sentimiento de plenitud de poseer y ser poseído por el mundo. Tal sentimiento ya en sí mismo representa la realización de aquello que gravita en la necesidad humana de teoría: la conciencia de sí; el conocimiento de

5 Armazón ideológica que sirve a la vez para legitimar socialmente a la teoría más allá de la verdad que ella busca mostrar de la realidad, llegando por esa vía incluso a convertirse en instrumento de dominación. 
sí mismo y, por ende, la conformación y legitimación de la identidad propia. El ser humano que por vía de la teoría puede poseer el mundo y ser poseído por él es consciente de sí mismo, de sus propias potencialidades y de sus limitaciones cognoscitivas y humanas: sabe quién es. Todo lo cual nos permite entrever las implicaciones de la cabal asunción de la elaboración teórica por parte de la investigación dentro de los campos del conocimiento.

Conforme un campo de conocimiento se autodefine hasta alcanzar su autonomía frente a los demás, se lleva a cabo en su interior el proceso de distinción y consolidación en cada una de las prácticas que lo constituyen. Cada práctica se distingue de las otras a partir de su organicidad lógica y de las funciones diferenciales que la constituyen; es sobre la base de esto que se definen, consolidan y establecen sus interrelaciones. La organicidad lógica y las funciones que caracterizan a la práctica de la investigación tienen la peculiaridad de que en ellas se procesa, genera y redistribuye el capital de conocimiento que circula en el campo. Tal función no es, por tanto, meramente administrativa o gestionaria del conocimiento, su complejidad exige una organización y sustentación igualmente complejas e implican peculiaridades y finalidades propias. Así, la práctica de investigación requiere estructurarse a partir de una concepción definida y programática del procesamiento, producción y objetivos del conocimiento. Lo que de una manera natural y hasta obvia termina conduciendo hacia la necesidad de asumir y perfilar la orientación teórica; la que incluso cabría decir que es una vocación de la investigación. Así la práctica de la investigación queda tensionada, dirigida, por la voluntad de teoría.

La teoría, entendida como teoría propia y no como importación yuxtapuesta, posibilita que la investigación constituya el analogon de aquella parte de la realidad que es el objeto de conocimiento de su campo, lo que le permite comprender su funcionamiento; esto es, devela su verdad oculta. El núcleo de ideas, columna vertebradora de la teoría, es aquel que se ha constituido a partir de sus objetos centrales de conocimiento y que marca la pauta en la conformación del paradigma articulador del campo de conocimiento. Paradigma que a su vez establece y marca las interacciones entre las ideas y la realidad, y posibilita la articulación del núcleo de ideas con las justificaciones empíricas, lógicas, ideológicas. Esta relación ontológica que establece la teoría propia de un campo de conocimiento con la parte de la realidad y sus objetos que le corresponden, contribuye decisivamente a la toma de conciencia del campo respecto de sí mismo: índice de autonomía (identidad) con relación a los demás campos de conocimiento. Esto le permite simultáneamente a la práctica de la investigación consolidarse para cumplir con la especificidad de sus funciones dentro del campo: ser articuladora de las interrelaciones entre 
las diversas prácticas. Articulación que lleva implícita una sustentación teórica, con la que a su vez les da un sustento teórico a las demás prácticas, para que éstas no se difuminen en la fugacidad del mero quehacer inmediato. Así, teniendo el soporte teórico que les brinda su práctica de investigación generan un conocimiento que tiene ese respaldo y que contribuye a su vez a incrementar el capital de conocimiento del campo, el cual es asimismo procesado por la investigación, la cual produce conocimiento sustentado teóricamente para redistribuirlo en las demás prácticas del campo. Círculo virtuoso de la investigación. Aquellos campos de conocimiento cuya práctica de investigación ha llevado a cabo su definición de una manera integral a partir de la sustentación y elaboración teórica son los que, dentro del Horizonte integrador social histórico de los campos de conocimiento, ${ }^{6}$ se muestran más claramente estructurados y constituidos. Desafortunadamente en el campo bibliotecológico esa situación no se presenta tan clara y definida.

El libro de N. Guevara, como a través de un escaparate, nos muestra de forma precisa la problemática que preexiste en el campo bibliotecológico entre la investigación bibliotecológica y la teoría; problemática expresada en oblicuos encuentros y perseverantes desencuentros. De ahí que entre la investigación bibliotecológica y la teoría exista una relación ambigua. Como se explicó con anterioridad, el libro de N. Guevara denota esa flagrante ambigüedad entre investigación y teoría: sabe de la necesidad de la teoría pero en el fondo la ve con reticencia, la solicita pero la limita, y la implementa sólo para apuntalar la aplicación inmediata, pero no para fundamentar la disciplina. Guevara hace una decidida mezcolanza de teorías “de paso" pero retrocede ante la asunción de la teoría per se para formular la teoría bibliotecológica, todo lo cual queda representado en su ambigüedad mayor: su visión dicotómica entre lo que denomina investigación pura e investigación aplicada. A su entender la investigación pura desarrolla un tipo de teoría que por su abstracción y falta de fines aplicables no tiene un contacto preciso con la realidad. En cambio en la investigación aplicada preexiste una especie de imperativo categórico que hace que cualquier teoría que se emplee muestre de inmediato sus rendimientos prácticos, que la hacen inalienable de la realidad, y para una disciplina como la bibliotecología esto es lo único posible. Dicotomía que en el fondo entraña un falso dilema y, por ende, una disyuntiva equívoca. Lo que esto pone en evidencia son las suspicacias y el desconocimiento de la historia de la teoría, así como de su esencia y sus potencialidades auténticas.

6 Para una más detallada explicación y aplicación de este concepto véase mi libro: Fundamentos de la constitución y autonomía del campo bibliotecológico: la bibliotecología española 1898-1936, México: UnAm, Centro Universitario de Investigaciones Bibliotecológicas, 2000. 
Estas ambigüedades que quedan de manifiesto en el libro Teoría y práctica de la Bibliotecología, no son privativas sólo de él, de hecho reflejan las ambigüedades que priman en este terreno del campo bibliotecológico. Lo que hace la investigación de N. Guevara es mostrar esto explícita y argumentativamente, sin que, obviamente, tal sea el cometido de la investigadora. Es una evidencia involuntaria lo que nos conduce a inquirir sobre el por qué de semejante ambigüedad y sobre cuál sería su posible resolución.

La respuesta a tales cuestiones se encuentra precisamente en su propio objeto de conocimiento y la forma en que éste, la biblioteca, ha sido comprendido. Objeto que desde su origen estuvo signado por la actividad práctica de recuperar, organizar, clasificar y difundir el conocimiento registrado. Por tanto el conocimiento generado por esa actividad debía responder a los requerimientos de explicación práctica; y no podía ser de otra forma porque además la biblioteca está inmersa en procesos sociales que la destinan a satisfacer necesidades inmediatas y concretas de información y comunicación. De ahí que la actividad y el conocimiento estén absortos en los procesos internos de la biblioteca, para así cumplir mejor y más eficientemente con tales funciones. Pero conforme la biblioteca amplifica y diversifica sus funciones se torna más compleja como objeto de conocimiento y entonces ya no es suficiente concebirla como entidad que requiere sólo de la actividad práctica, aunque sigue predominando el dictum pragmático. Esto va a propiciar el desenvolvimiento de un pensamiento bibliotecario que tiene importantes vertientes reflexivas y conceptuales, lo que viene a constituirse en un intento primigenio de darle una explicación al fenómeno bibliotecario con mayor elaboración, lo cual a su vez genera un conocimiento propio para dar razón de sí, que ya no obedece a la total servidumbre del dictum pragmático. Pensamiento bibliotecario que en cuanto tal crea un bagaje de conocimiento de mayor elaboración sobre el que se sustenta el fenómeno bibliotecario. Así, por un lado, prima la orientación exclusivamente pragmática y, por el otro, hay una orientación en la que el pragmatismo se funde en formas más elaboradas de explicación. Será ésta la base para diferenciar las prácticas cuando sobrevenga el proceso de constitución del campo bibliotecológico. Este desenvolvimiento que obedecía a su natural tendencia evolutiva y que orientaba a la bibliotecología será removido por el impacto de la expansión técnoinformativa, y ello producirá el bloqueamiento de la continuidad del pensamiento bibliotecario en aras de mimetizar al campo con las tendencias en boga. Y también obstaculizará aquella práctica a la que conduce el pensamiento bibliotecario: la investigación.

Así, a partir de un código no escrito, la producción cognoscitiva de la investigación bibliotecológica queda signada por el conocimiento aplicado. Con lo que la mirada cognoscitiva queda una vez más absorta en los procesos 
funcionales de la biblioteca. Y no se vislumbra que desde el momento en que se inicia la constitución del campo, con su diferenciación de prácticas internas, se establecía una distinción entre los procesos pragmáticos de la biblioteca y el conocimiento generado en la investigación. Distinción, pues, marcada por la forma de asunción de la teoría, que en el mejor de los casos, como lo encarna N. Guevara, usa limitada y reticentemente la teoría, mientras que en otros surge un decidido rechazo de ella bajo el supuesto (que puede ser temor o desconocimiento) de que la teoría por sí misma deriva en el abstraccionismo que desorienta el dictum pragmático esencial a la bibliotecología. He aquí, pues, el origen de la ambigüedad.

Para superar semejante ambigüedad es menester que la propia investigación tome conciencia de su especificidad y diferenciación y, por ende, de sus funciones y objetivos respecto a las demás prácticas del campo, y asuma con ello la necesidad de hacer una elaboración teórica como factor sustentante de la investigación, pero además como vía indispensable para construir la teoría bibliotecológica. Esta asunción de la necesidad de teoría no ha de caracterizarse por la yuxtaposición de teorías foráneas, sino por la asimilación y reelaboración crítica de ellas. La construcción de la teoría bibliotecológica ha de tener como basamento de su núcleo de ideas el bagaje de conocimientos acumulados que le proporciona el pensamiento bibliotecario, "los cuales responden a las grandes obsesiones cognitivas" de la disciplina, la que a su vez recibe la sustentación teórica que requiere, sistematizando y fundamentando sus logros reflexivos y conceptuales.

La asimilación y utilización del pensamiento bibliotecario por parte de la teoría permitiría restablecer la unidad y continuidad de la bibliotecología con su propio pasado, y contrarrestaría el mimetismo que el impacto de movimientos y tendencias en boga le ocasiona; cosa que reafirmaría lo que en verdad es, para no distorsionarse y confundirse con lo que en realidad no es, aunque preexista un profundo parentesco. La bibliotecología no es (y nunca lo será) una tecnología social, hace uso de la tecnología, que es muy distinto. Es a partir de la conformación de su propia teoría como podrá hacer frente de manera cognoscitiva y crítica a los procesos y cambios exteriores, como el impacto tecnoinformativo, para tomar de ellos lo que le sea conveniente para sus propias necesidades sin desvirtuarse a sí misma. Igualmente desde su plataforma teórica podrá darles una sólida fundamentación teórica a sus propios objetos de conocimiento, por encima de los vertiginosos y constantes cambios a que está expuesto el fenómeno bibliotecario en su conjunto.

Ubicándonos en el terreno inmediato y concreto, cada investigador en algún momento de su carrera profesional habrá de plantearse la necesidad de teoría a que se ha hecho repetidamente referencia, lo que implica que deberá asumir la parte que le corresponde de su contribución a la construcción de 
la teoría bibliotecológica; para lo cual tendrá que buscar fundamentar teóricamente aquel objeto u objetos de conocimiento centrales de su línea de investigación. Lo que irá conformando un capital de conocimiento teórico de cada objeto o sector de conocimiento de la bibliotecología. Capital que al irse conjuntando, depurando y sistematizando desembocará gradualmente, y por sí mismo, en la construcción de la teoría bibliotecológica: columna vertebradora de esta disciplina, que es la cubierta del campo. Con la teoría bibliotecológica, como explica Edgar Morin, se podrá forjar el analogon abstracto/ideal del funcionamiento de esa parte del universo correspondiente a lo bibliotecológico, y contemplará así su verdad oculta.

$\mathrm{Al}$ adentrarse en el complejo territorio de la teoría, el investigador bibliotecólogo obtendrá un fundamento más consistente para sus investigaciones y les dará una mejor salvaguarda contra la erosión del cambio que se da constantemente en los objetos de conocimiento que investiga en su quehacer cognoscitivo. Pero también con ello contribuirá a la definición y consolidación de la práctica de investigación a la cual pertenece. Lo que implicará que el investigador bibliotecólogo habrá de despojarse de las suspicacias, desconocimientos y ambigüedades que guarda respecto de la teoría. Es cierto que la teoría contiene en sí una dimensión de fascinación y encantamiento que puede conducir a su alejamiento de la realidad que la propició y a la cual busca dar razón, y conlleva el riesgo de hundirse en la mera abstracción e incluso ésta convertirsee en dictadora de esa realidad, como lo selló Hegel en su multicitada frase en la que decía que era peor para la realidad si ésta no respondía a los designios lógicos de la teoría. Contra esta obnubilación de la teoría respecto a la realidad también nos previene Edgar Morin:

Toda adhesión a un sistema coherente de ideas sobre el mundo permite concebir el mundo como un sistema ordenado y perfecto. En ese sentido la pasión "parmenidea" de la Unidad borra los desórdenes, las pluralidades, los desarraigos, las parcelaciones, las diásporas de todas las cosas, que entonces semejan apariencias superficiales; la sed lógica de Unidad es también sed mística. En este sentido, igualmente la concepción de un mundo que fuera una máquina determinista impecable satisface una obsesión de perfección y de incorruptibilidad. Por último, cuando la racionalidad se degrada en racionalización, permite encerrar de forma mágica/analógica al mundo en el sistema concebido por el espíritu... ${ }^{7}$

La racionalización, que no la racionalidad, propicia que la organización lógica, abstracta, que conforma a una teoría y que le da forma a una visión del

$92 \quad 7 \quad$ E. Morin, op. cit., p. 146. 
mundo quede estatuida en un sistema cerrado y perfecto, donde "el sonido y la furia" de la pluralidad, el desorden, lo fugaz y lo efímero no tienen cabida. De esta manera la teoría pierde el contacto con la realidad inmediata de la cual y para la cual nació: girando incorruptible e inmarcesible en su perfección abstracta sin contaminación de los avatares imperfectos y corruptores de lo concreto. Y no hay cosa que produzca más angustia en la mentalidad pragmática que la separación del suelo de sus seguridades, la realidad inmediata. ${ }^{8}$ Al bibliotecólogo por una tradición de conocimiento aplicado que lo protege contra los riesgos intelectuales, no hay cosa que lo angustie más que distanciarse a partir de la teoría de su objeto de conocimiento, puesto que vislumbra a la teoría a partir del peligro de su racionalización, que la separa de la realidad inmediata. Por tanto, para evitar esa angustia justifica y valida como única opción epistemológica para la bibliotecología la investigación aplicada, de allí que sólo con reserva haga uso instrumental de algunas teorías. Pero esto, obviamente, es una salida ficticia para evadir el teoricismo, la racionalización teórica. Como se adelantó anteriormente, la salida a esta encrucijada se encuentra en los propios objetos de conocimiento de la bibliotecología.

A diferencia de la filosofía, cuyos objetos de conocimiento no son entidades concretas, fenoménicas, la bibliotecología está dirigida hacia objetos tangibles inmediatos y su propio objeto de conocimiento afinca firmemente su teoría en la realidad. Cualquier construcción teórica que se lleve a cabo en su práctica de investigación, de una u otra forma estará impelida por su propio objeto de conocimiento a dirigirse a la realidad. Incluso como medida de control para que no haya separaciones o desviaciones de las relaciones adecuadas que han de conservar teoría y realidad, es menester implementar el procedimiento epistemológico que Gastón Bachelard definía como vigilancia de vigilancia, esto es, que a la vigilancia que se lleva a cabo sobre el objeto y sobre la aplicación de los instrumentos de conocimiento (p. ej. el método) se ha de añadir la vigilancia sobre esos instrumentos mismos. Con lo que se estará ejerciendo una constante crítica del proceso de conocimiento que vincula teoría y realidad. De este modo la angustia ante el teoricismo queda conjurada y la ambigüedad queda así también difuminada, lo que deja abierta, pues, la necesidad de asumir la teoría sin reservas como vía real para fundamentar la disciplina y consolidar la investigación. Ésta es, por tanto, la paradoja de semejante

8 Un poco, como diría Alfonso Reyes, entre burlas y veras: Freud consideraba que una de las fuentes generadoras de la angustia es la negación de satisfacer un síntoma, que a su vez es resultado de una represión. Traducido a nuestra argumentación, puede decirse que la mente, en su afán imaginativo y creativo (principio del placer) de expansión comprensiva del mundo, es reprimida en ese impulso, por la necesidad de ceñirse a la realidad inmediata concreta (principio de la realidad); lo cual genera un síntoma que desencadena la angustia y que es evitada aferrándose los pragmatistas aún más a sus seguridades en la concreción. 
objeto de conocimiento de la bibliotecología: por un lado queda envarada en la orientación pragmática que le impide ver más allá de ese terreno inmediato; pero por el otro cuando se decide ver hacia el cielo de la teoría tiene el ancla que la fija a la realidad, impidiéndole la fuga hacia el mundo obturado del teoricismo. Además, si se desarrolla la auténtica teoría en la investigación, ésta, por sí misma muestra su vertiente práctica, y ello no a la confusa manera como lo preconiza el título del libro de N. Guevara Teoría y práctica de la Bibliotecología. Todo lo cual pone en evidencia la falsa disyuntiva que representa la diferencia entre investigación pura e investigación aplicada. Sólo bay investigación sin más y es aquella que asume sin angustia y sin perspicacia, sin ambigüedad, la construcción teórica, cuya otra cara es la extensión práctica: abstracto y concreto, subjetivo y objetivo los dos rostros de ese Jano que es la teoría auténtica. Por lo que aquí bien caben las palabras de Pierre Bourdieu que dejan claramente establecida la unidad entre teoría y realidad que ha de dirigir la orientación de la investigación:

Y, por ello pueden resultar interesantes para que los que deseen seguir una investigación de acuerdo con la lógica de su desarrollo y llevarlos al convencimiento, que yo siempre he tenido, de que cuanto más profundiza el análisis teórico, más cerca está de los datos de la observación.?

De hecho una práctica de la investigación que mire hacia delante y que pretenda ser generadora de un conocimiento científico riguroso e innovador para su campo, ha de establecer la unidad del continuum entre ambas formas de investigación:

Hay que acabar, pues, con la división radical entre la investigación básica y aplicada, que, aunque es una realidad histórica de la ciencia, que se extiende a todos los campos de conocimiento, empieza a estar superada. Los límites donde termina una y comienza la otra cada día están más borrosos. Se está llegando hoy a la noción de continuum entre los diferentes tipos de investigación. ${ }^{10}$

9 P. Bourdieu, El baile de los solteros, Barcelona, Anagrama, 2004, p. 11.

10 E. Delgado López-Cózar. La investigación en biblioteconomía y documentación. Guijón, TREA, 2002, pp. 233-234. "De ahí que el papel que debe jugar la investigación (biblioteconómica) dentro de la profesión (...) sea incrementar la comprensión del contexto en la práctica profesional, proveyéndola de un marco teórico para el análisis, prescripción (recomendación), tratamiento (implementación) y evaluación con el propósito de facilitar la transferencia de la información. La teoría suministra los conceptos subyacentes y los métodos para diagnóstico y resolución de los problemas, mientras que la práctica proporciona los problemas y las pruebas de utilidad de los resultados. Las disciplinas profesionales más maduras como la medicina han desarrollado áreas de conocimiento básicas que la dotan de una amplia base teórica. Esa debe ser nuestra aspiración”. Ibid., p. 233. 
Por otra parte, al ser asumida la construcción teórica y la teoría en sí misma como un proyecto orgánico y sistemático por la investigación,se ponen las bases para la elaboración de la teoría bibliotecológica, lo que a su vez ayudará a autodefinir y consolidar la propia práctica de la investigación dentro del campo. Pero cabe subrayar que aquí teoría bibliotecológica ha de comprenderse como el conjunto articulado de las teorías regionales del campo bibliotecológico; esto es, aquella teoría que a la vez muestra y da explicación de la lógica relacional preexistente entre cada una de las prácticas que integran al campo. La teoría bibliotecológica no debe ser entendida, construida, como una teoría absolutista y monolítica, la cual correría el riesgo de ser inmediatamente rebasada por los constantes cambios que produce el desenvolvimiento específico de las prácticas. Además una teoría absolutista de esa índole acabaría convirtiéndose en sí misma en una rémora que, más que contribuir a develar la verdad del campo lo ocultaría bajo el abstraccionismo. De esta forma la investigación se ubica en el punto estratégico dentro del campo para llevar a cabo su función de articulación de las demás prácticas a partir de la base teórica de conocimiento que les brinda. Así la dinámica interrelacional de las prácticas del campo articulada por la investigación desde la plataforma teórica, conducirá a la unidad y toma de conciencia del campo respecto a su identidad diferencial y autónoma con relación a los demás campos de conocimiento, con lo que estará a la vez mejor equipado el campo bibliotecológico para hacer frente a todas aquellas tendencias que lo impactan y que lo han llevado al mimetismo con aquello que él no es. La senda para salir de la ambigüedad queda así señalada para la investigación bibliotecológica: la voluntad de teoría.

París, Maison du Mexique, otoño del 2004.

\section{BiBLIOGRAFÍA.}

Alfaro López, Héctor G., Fundamentos de la constitución y autonomía del campo bibliotecológico: la bibliotecología española 1898-1936, México: UNAM, Centro Universitario de Investigaciones Bibliotecológicas, 2000

"La otra lectura. Una contribución al problema de la lectura en Bibliotecología”, en Revista de Investigación Bibliotecológica.

Bachelard, Gastón. Le rationalisme appliqué. París, PUF, 2004 La philosophie du non. Essai d'une philosophie du novel esprit scientifique, Paris, PUF, 1970.

Barreau, H., L'epistemologie, París, PUF, 1990.

Bourdieu, Pierre, Choses dites, París, Minuit, 1987. 
Questions de sociologie, París, Minuit, 1981. d'agir, 2001.

Brunschwig, Jacques et Lloyd, Geoffrey, Le Savoir grec, Paris, Flamarion, 1996.

Delgado López-cózar, E. La investigación en bilioteconomía y documentación. Guijón, TREA, 2002.

Encrevé, Pierre et Langrave, Rose-Marie (direction), Travailler avec Bourdieu, Flammarion, 2003.

Froissart, F., et Hecquard, F. (coordination), Le métier de bibliothécaire, París, Editions du Cercle de la Librairie, 1993.

Goldhor, Herbert, Introducción a la investigación científica en Bibliotecología, México, UNAM, 1981.

Granger, G., La raison, París, PUF, 1965.

Guevara, Neysa, Teoria y práctica de la Bibliotecología, Caracas, Fondo Editorial de la Facultad de Humanidades y Educación de la Universidad Central de Venezuela, 1995

Morin, Edgar, El método. El conocimiento del conocimiento, Madrid, Cátedra, 1994.

La tête bien faite. Repenser la réforme, reformer la pensée, París, Seuil, 1999.

Orera Orera, Luisa (editora), Manual de Biblioteconomía, Madrid, Síntesis, 1997.

Shera, Jesse, Los fundamentos de la educación bibliotecológica, México, UNAM-CUIB, 1990. 